АЛЬОШИН Г. В., д.Т.н., професор (Український державний університет залізничного транспорту)

\title{
Головні переваги сепарабельного програмування багатовимірних задач
}

ДЛя

У задачах підвищення ефективності інформаційно-вимірювальних систем (IBC) суттєву роль відіграють методи і алгоритми розв 'язання задач, які у значній мірі визначають їх реалізацію та якість.

Вибір кращого методу для таких задач звичайно формулюється у вигляді математичного програмування. У статті показано, щзо таким методом може бути сепарабельне програмування, яке дає значні переваги перед іншими методами.

Публікації задач оптимізащії різних IBC та їх функціональних елементів (ФЕ) [1 - 4] підтверджують можливість використання пропонованого методу.

Ключові слова: сепарабельне програмування, багатовимірні задачі.

\begin{abstract}
Аналіз якості методів оптимізації ІВC
Питанням вибору ефективного методу розв'язання задач математичного програмування у математиці присвячені численні публикації.

Методи класифікуються за формами виразів цільової функції та функцій зв'язку: методи прямого пошуку - дихотомія, за числами Фібоначчі та ін.; методи лінійного програмування - симплекс-метод, метод обернення матриці коефіцієнтів та ін.; нелінійні методи - опукле програмування - градієнтні методи першого та другого порядку і т. ін.

Але нас не можуть задовольняти такі умови, особливо тоді, коли у результаті обробки статистики, при отриманні ліній середньоквадратичної регресії нечіткої вартості на параметр, змінюються форми функцій зв'язку, а отже, i методи математичного програмування при розв'язанні задач. Нам потрібний єдиний універсальний метод, який би не залежав від форми функцій зв'язку і задовольняв би такі вимоги,
\end{abstract} як:

1) універсальність;

2) спрощення розв'язання задач великої розмірності;

3) простота алгоритму;

4) збіжність, або малий час розв'язання задач;

5) контрольованість результатів;

6) наочність, або простота перевірки опуклості, або одномодальності, та інших якостей;

7) оцінка критичності, або залежності оптимуму від сталих і інших факторів;

8) простота отримання кривих обміну [5].
3 точки зору вимоги 1 найбільш задовольняє відомий метод Вульфа [6], при якому лінеаризуються опуклі цільова i функції зв'язку. Тобто задача зводиться до відомого лінійного програмування. Це універсальний метод, придатний для будь-якої задачі, при якому задача спрощується і зводиться до лінійного програмування, що використовується ітеративно. Але він не задовольняє інші вимоги. Інші методи не універсальні і особливо неприйнятні для задач великої розмірності.

Метою роботи є визначення якості такого методу оптимізації, який задовольняв би вказані вимоги.

При всій універсальності недоліки методу Вульфа - саме у лінеаризації всіх функцій, що призводить до суттєвого зменшення кроку ітерації за кожним параметром і збільшення числа ітерацій.

Якщо не лінеаризувати функції, то можливе нелінійне програмування, яке буде мати якості градієнтних методів і зможе адаптувати крок. Вони складніші.

Більшість постановок задач підвищення ефективності і оптимізації IBC містять цільову функцію за головним показником системи і функцію зв'язку, яка звичайно буває вартістю, або витратним показником.

У цих умовах, коли маємо нечіткий показник вартості, доцільно лінеаризувати лише функцію зв'язку. Тоді для спрощеного розв'язання задачі (в аналітичному вигляді) достатньо мати сепарабельну цільову функцію, яку можна перетворити у сепарабельну однотипну функцію. Покажемо це на прикладі, коли критерій точності вимірювального каналу залежить від максимуму відношення сигналу до шуму:

$$
\max q(\bar{X}(\bar{Y}))=\prod_{i=1}^{n} X_{i}\left(Y_{i}\right)
$$


де $n$ - число параметрів, $X_{i}\left(Y_{i}\right)$ - «фазовий» параметр (ФП), тобто складна монотонна функція від технічного параметра $Y_{i}$, причому ФП відображає вплив технічних параметрів і функцій розладів, збурень i неідеальностей системи на відношення сигналу до шуму $q(\bar{X}(\bar{Y}))$.

Функція зв'язку $\varphi(\bar{Y})$ може мати будь-який вигляд, тому що при лінеаризації функції вартості $C(\bar{Y})$ в околі $Y_{i 0}$ вона завжди стає сепарабельною:

$\varphi(\bar{Y})=C_{\partial}-C(\bar{Y})=C_{\partial}-\sum_{i=1}^{n}\left[C_{i}\left(Y_{i 0}\right)-C_{i}^{\prime}\left(Y_{i 0}\right)\left(Y_{i}-Y_{i 0}\right)\right] \geq 0$,

тобто

$\left.\sum_{i=1}^{n} C_{i}^{\prime}\left(Y_{i 0}\right) Y_{i}\right] \leq C_{e}$,

де $C_{e}=C_{\partial}-\sum_{i=1}^{n}\left[C_{i}\left(Y_{i 0}\right)+C_{i}^{\prime}\left(Y_{i 0}\right) Y_{i 0}\right]$,

$C_{\partial}$ - допустиме значення вартості.

Задача (1), (2) нелінійного програмування також може бути складною. Тому заміною технічних параметрів на «фазові» параметри задача стає простою і вирішується в аналітичному вигляді.

\section{Ідея спрощення такої задачі}

Функція Лагранжа задачі (1), (2) є:

$L(\bar{X})=\prod_{i=1}^{n} X_{i}+\left[C_{\partial}-\lambda \sum_{i=1}^{n} C_{i}^{\prime}\left(X_{i 0}\right) X_{i}\right]$

Отримуємо систему рівнянь:

$\forall k \in[1, n] \rightarrow \frac{\partial L}{\partial X_{k}}=\frac{a}{X_{k}}-\lambda C_{k}^{\prime}\left(X_{k 0}\right)=0$

Оскільки складові цільової функції однотипні, невизначений розв'язок дорівнює:

$$
X_{k}=\frac{a}{\lambda C_{k}^{\prime}\left(X_{k 0}\right)}
$$

Тому нема потреби розв'язувати систему рівнянь (3), оскільки вони ідентичні. Невизначений множник можна отримати, якщо формулу (4) підставити у формулу (2), визначити $\lambda$ і підставити у формулу (4). Тоді

$\sum C_{k}^{\prime}\left(X_{k 0}\right) \frac{a}{\lambda C_{k}^{\prime}\left(X_{k 0}\right)}=C_{e}, \lambda=\frac{n a}{C_{e}}, X_{k}=\frac{C_{e}}{n C_{k}^{\prime}\left(X_{k 0}\right)}$

Результат дорівнює

$$
\max q(\bar{X})=\frac{\left(C_{e} / n\right)^{n}}{\prod_{k=1}^{n} C_{k}^{\prime}\left(X_{k 0}\right)} .
$$

Технічні параметри отримують із зворотних функцій $Y_{k}=Y_{k}\left(X_{k}\right) .3$ результату у вигляді формули (6) вже видно залежність оптимуму від відношення середньоарифметичної частини до середньогеометричної частини, також незначне зростання складності алгоритму від розміру задачі і т. ін.

Таким же чином вирішуються проблеми і задачі підвищення ефективності i оптимізації будь-якого призначення [1 - 4].

Врахування вартості - це крок вперед в оцінці якості IBC. Найкраще, якщо вона враховується на основі маркетингової статистики.

Врахування вартості, яка є нечіткою величиною зі своєю волантильністю, доцільне на період іiі стабільності.

Далі буде розглянуто прості та більш складні приклади оптимізації IBC тим самим методом, що покаже можливість алгоритму для зшивання часткових результатів.

Дисперсія похибки вимірювальної IBC або каналу за рахунок випадкової шумової складової похибки для дискримінаторів має вигляд [3, 4]:

$$
\sigma_{\lambda}^{2}=\frac{\Delta \lambda^{2}}{q}=\frac{1}{(\Delta \lambda)^{-2} q}=\frac{\text { const }}{\prod_{j=1}^{n 1} X_{j}\left(Y_{j i}\right)},
$$

де $\Delta \lambda$ - апертура, діапазон однозначності відрахування оцінки, або діапазон дискримінатора;

$q$ - відношення потужностей сигналу до шуму [2];

$X_{j}\left(Y_{j i}\right)$ - функції монотонних залежностей від технічних параметрів, які впливають на $j$-й показник IBC.

Завадостійкість неперервної IBC залежить від відношення сигнал/шум $q$, а у разі інформаційної цифрової системи $3 m_{1}$ ортогональними сигналами ймовірність помилки $\epsilon$ : 
$p_{\text {oucp }}=\sqrt{m_{1}-1} \exp \left(-\frac{q_{n}}{2}-1,4\right)$,

де $q_{n}-$ співвідношення сигнал/шум на виході приймача, або зворотно пропорційне відношенню потужностей сигналу до шуму (6) і дорівнює:

$$
\frac{1}{q_{n}} \leq \frac{1}{2 \ln \frac{\sqrt{m_{1}-1}}{p_{\text {uдоn }}}-2,8}=\frac{1}{q_{n}}=\frac{\text { const }}{\prod_{j=1}^{n 1} X_{j}\left(Y_{j}\right)}
$$

Очевидно, що найбільшу завадостійкість чи найбільшу точність повинні мати однофункціональні (одноканальні) системи 3 показниками (1), (2). Такі показники можуть служити цільовою функцією багатьох задач оптимізації.

Для них цільова функція може бути зворотною по відношенню до $q$ :

$$
\min q^{-1}(\bar{X})=k_{1} \frac{1}{\prod_{j=1}^{n 1} X_{j}}
$$

При тому ж обмеженні за вартістю задача має розв'язання (7) i зворотно пропорційний результат $(7, a)$.

$$
X_{i(p)}=\frac{C_{\ni 1}\left(\bar{X}_{(p-1)}\right)}{n 1 C_{i}^{\prime}\left(X_{i(p-1)}\right)},
$$

де $p$ - номер ітерації,

та оптимум

$$
F\left(X_{o p m}\right)=q^{-1}\left(\bar{X}_{o p m}\right)=\frac{k_{1} \prod_{j=1}^{n 1} C_{j}^{1}\left(X_{j(p)}\right)}{\left[C_{\ni 1}\left(\bar{X}_{(p)}\right) / n 1\right]^{n 1}}
$$

Якщо обмеження нелінійні, то перші значення вектора параметрів і вартостей ФЕ, які $\epsilon$ початковим планом, підставляються у формулу для отримання вектора розв'язання першої ітерації. Процес ітерацій продовжується до отримання оптимальних рішень за показником, параметрами та вартістю ФЕ.

На відміну від методу Вульфа тут відбуваєтся: 1) розв'язання простішої задачі будь-якого розміру в аналітичному вигляді, 3 користанням сепарабельності функцій, що відразу дає уявлення про характер оптимуму; 2) використання достатньо простого розв'язку, отриманого в аналітичному вигляді (у вигляді формули) як ітеративного розв'язку (i вирішення проблеми багатовимірності); 3) якщо функція зв'язку була лінійна, то це кінцевий розв'язок; 4) якщо ні, то його можна оцінити за критерієм близькості апроксимації (до 10 \% початкової функції) за всіма параметрами $\Delta X_{i} \leq \frac{0,2 C_{i}^{\prime}\left(X_{i}\right)}{C_{i}^{\prime \prime}\left(X_{i}\right)}$, де $C_{i}^{\prime \prime}\left(X_{i}\right)$ - друга похідна вартості; 5) для параметрів, які за областю задовільної апроксимації, треба обмежити крок до межі цієї області.

Правилом зупинки може служити критерій точності розв'язку

$$
X_{j(p)}-X_{i j p-1)} \leq \sigma X_{j(p-1)}
$$

де $j$ - номер параметра; $p$ - номер кроку ітерації; $\sigma=0,1$, тобто $0,1=10 \% \quad-\quad$ відносна точність розв'язку.

Цей розв'язок має такі переваги перед відомими методами математичного програмування: 1) вирішується проблема багатовимірності, можливе врахування усіх параметрів; 2) простіше розв'язуються задачі на умовний екстремум, тим більш при одній функції зв'язку не треба розв'язувати систему нелінійних рівнянь; 3) програма стає універсальною за відношенням до форми цільової функції і будь-яких функцій зв'язку, а при повному наборі розв'язаних простіших задач вона може бути універсальною і для різних класів цільових функцій; 4) очевидний характер випуклості або увігнутості і впливає лише на наявність потрібного екстремуму; 5) значення у числах використовуються тільки в процедурі ітерацій; 6) результат отриманий у вигляді алгоритму та оптимуму в аналітичному вигляді та придатний для аналізу в області задовільної апроксимації, що особливо важливо при стохастичному програмуванні для визначення довірчих інтервалів; 7) технічні параметри відшукуються у вигляді обернених функцій «фазових» параметрів; 8) результат оптимізації, отриманий в аналітичному вигляді, придатний для аналізу ефективності і як «крива обміну» за Л. С. Гуткіним [5]; 9) допустимо розв'язувати задачі частинами, а потім їх зшивати; 10) «криві обміну» дозволяють також більш об'єктивно оцінювати ефективність структур та сигналів, якщо IBC оптимізувалися майже за однаковими показниками [1].

Таким чином, у даному прикладі оптимізації простежується головна ідея нового методу математичного програмування, яка усуває згадані недоліки існуючих методів, які позначені у вимогах до методу. Ця ідея використовує лінійну апроксимацію складної сепарабельної функції зв'язку і однотипність цільової функції.

При цьому сепарабельність функції зв’язку необов'язкова, тому що лінеаризація будь-якої функції 
обмежень призводить до лінійної, а отже, до сепарабельності апроксимації. А сепарабельність цільової функції забезпечується монотонним перетворенням змінних.

Наступна суттєва перевага сепарабельного програмування полягає у тому, що можна частинами, як у блочному програмуванні, розподіляти задачі програмування, а далі зшивати їх результати.

Розглянуту задачу оптимізації частини системи, яка призначена для боротьби із завадою, тобто для підвищення відношення потужності сигналу до шуму, розширимо для врахування впливу похибок еталонів на результуючу похибку вимірювань:

$F=\min \left[\frac{k_{1}}{\prod_{j=1}^{n 1} X_{j}}+\sum_{i=1}^{n 2} X_{i}^{2}\right]$

при $C(\bar{X}) \leq C_{\partial o n}$,

де $k_{1}=$ const,$X_{j}$ - монотонні функції технічних та паразитних параметрів впливу розладів, збурень та неідеальностей, такі що чим вони більші, тим краще, а $\mathrm{X}_{\mathrm{i}}$ - похибки за рахунок нестабільності еталонів, які чим менші, тим краще для системи.

Асигнування на параметри першої складової у формулі (8) роздільні від асигнувань на параметри другої складової. Тому тут є дві стандартні задачі: за типом (4), (5) і за типом (8), (8,a) - мінімум другої складової при обмеженнях на свої асигнування $C_{\partial 2}$ :

$\min \sum_{i=1}^{n 2} X_{i}^{2}$

при $C_{(i))}\left(\bar{X}_{(i)}\right) \leq C_{\partial 2}$

або

$\sum_{i=1}^{n 2} C_{i}^{1}\left(X_{0 i}\right) X_{i} \leq C_{\ni 2}, C_{\ni 2}=C_{\partial 2}-\sum_{i=1}^{n 2}\left[C_{i}\left(X_{0 i}\right)-C_{i}^{1}\left(X_{0 i}\right) X_{0 i}\right] \cdot$

Функція Лагранжа для задачі (9), (10) має вигляд:

$L_{2}=\sum_{i=1}^{n 2} X_{i}^{2}+\lambda_{2}\left[C_{\ni 2}-\sum_{i=1}^{n 2} C_{i}^{1} X_{i}\right]$
3 умови $\frac{\partial L_{2}}{\partial X_{k}}=2 X_{k}-\lambda_{2} C_{k}^{1}=0 \quad$ отримаємо значення $X_{k}=\lambda_{2} C_{k}^{1} / 2$, яке підставляємо в умову (10) для отримання значення $\lambda_{2}$.

Тоді друга задача має аналітичний розв’язок i оптимум відповідно:

$$
\begin{aligned}
& X_{i(r)}=\frac{C_{\ni 2}\left(\bar{X}_{(r-1)}\right) C_{i}^{\prime}\left(\bar{X}_{i(r-1)}\right)}{\sum_{i=1}^{n 2}\left[C_{i}^{\prime}\left(X_{i}\right)\right]^{2}} \\
& F_{2}\left(C_{\ni 2}\right)=\frac{C_{\ni 2}}{\sum_{i=1}^{n 2}\left[C_{i}^{\prime}\left(X_{i}\right)\right]^{2}}
\end{aligned}
$$

Зшити розв'язки двох задач (7), (7,a) і (11), (12) можна розв'язанням послідовної більш простої двовимірної задачі:

$$
\begin{aligned}
& \sigma_{\lambda}^{2}=F_{1}\left(C_{\ni 1}\right)+F_{2}\left(C_{\ni 2}\right) \\
& C_{\ni 1}+C_{\ni 2} \leq C_{\ni}
\end{aligned}
$$

Розв'язок може бути отримано методом НьютонаРафсона у вигляді ітеративної формули.

Наприклад, оптимум задачі (8), (9) можна знайти при вже відомих оптимумах двох локальних задач:

$$
F=\frac{A}{C_{\ni 1}^{n 1}}+\frac{C_{\ni 2}^{2}}{B}
$$

при $C_{\ni 1}+C_{\ni 2}=C_{\ni}$,

де $A=n 1^{n 1} \prod_{j=1}^{n 1} C_{j}^{\prime}, B=\sum_{m=1}^{n 2}\left(C_{i}^{\prime}\right)^{2}$.

Задача розв'язується за одною змінною, наприклад, методом підстановки. Рішення знаходиться 3 умови $\frac{d F}{d C_{э 1}}=0$ в аналітичному вигляді методом Ньютона-Рафсона $з$ рівняння:

$C_{\ni 1}=C_{\ni}-\frac{D}{C_{\ni 1}^{n 1+1}}$

де $D=\frac{n_{1} A B}{2}$. 
Однотипність функцій досягається нескладно, заміною змінних задачі на «фазові» параметри. Новий метод сепарабельного програмування також добре працює і для цільової функції як у вигляді добутку однотипних функцій, так i у вигляді додатка при відповідних монотонних змінних:

$\min q=\min \prod_{i=1}^{n} X_{i}\left(Y_{i}\right)=\min \left[\exp \sum_{i=1}^{n} \lg X_{i}\left(Y_{i}\right)\right]$

Наприклад, призначимо $Z_{i}\left(X_{i}\right)=\lg X_{i}\left(Y_{i}\right)$ i $C_{i}\left(X_{s}\right)=C_{i}\left(\exp Z_{i}\right)$.

I навпаки, додаток функцій у функції цілі можна представити як добуток змінених функцій.

Якщо різні частини задачі, то можливе нескладне зшивання результатів оптимізації. Причому спрощення цільової функції призводить до монотонного ускладнення обмежень за вартістю, які враховуються при розрахунку похідних від складних функцій.

Згадані особливості нового методу сепарабельного програмування i отримання вказаних переваг нескладно пристосувати практично до будь-якої задачі оптимізації однофункціональних та багатофункціональних IBC або їх інформаційних та вимірювальних каналів [1 - 4].

\section{Висновки}

У нового методу сепарабельного програмування немає недоліків, які згадані раніше і подані як вимоги до потрібного методу оптимізації. Він вирішує проблему багатовимірності, збіжності, простоти, побудови кривих обміну та ін. Тобто новий метод оптимізації систем та мереж має такі переваги перед існуючими методами:

- проблема багатовимірності впливає тільки у першому порядку;

- універсальність алгоритму оптимізації для довільних сепарабельних функцій;

- ітеративний процес швидко збігається, як i y градієнтному методі другого порядку з регулюванням кроку ітерації;

- розв'язок отриманий у загальному (аналітичному) вигляді, що дає змогу одразу отримати криві обміну i спростити процедуру системного аналізу результатів оптимізації;

- аналітичний вигляд розв'язку та оптимуму дає змогу одразу бачити та прогнозувати, які виробництва і якості IBC і їх ФЕ потрібно розвивати;

- метод особливо зручний для розв'язання багатопараметричних задач iз сепарабельними функціями мети і де функціями зв'язку є асигнування на систему, оскільки ці асигнування завжди $\epsilon$ глобальними обмеженнями;

- отримати розв'язки складних зіставних задач блочного програмування простіше [1-4], тому що вони зшиваються із розв'язків та оптимумів більш простих стандартних задач;

- навіть коли отримані оптимуми складні для аналітичного системного аналізу, їх числовий аналіз ефективності простіший, і усі інші переваги методу зберігаються;

- отримані алгоритми розв'язань нескладно програмувати на ЕОМ;

- новий метод може використовуватись і для несепарабельних цільових функцій, якщо їх розкласти у поліноміальні ряди низьких порядків. Але при цьому ефективність методу знижується до ефективності методу Вульфа;

- на відміну від звичайних методів проектування IBC або інших систем, де інтуїтивно назначають параметри $Y_{j i} \Phi Е$, пропонується використовувати усю можливу маркетингову статистику, що суттєво, майже на порядок і більше, підвищує ефективність систем.

Останнє пояснюється тим, що навіть досвідченому експерту при заданих нелінійних функціях важко точно вгадати, де може бути оптимум.

\section{Список літератури}

1. Алешин, Г.В. Эффективность сложных радиотехнических систем [Текст]: монография / Г. В. Алешин, Ю. А. Богданов. - К.: Наукова думка, 2008. - 288 с.

2. Альошин, Г.В. Оцінка якості інформаційновимірювальних систем [Текст] / Г. В. Альошин. Харків: УкрДАЗТ, 2009. - 300 с.

3. Алешин, Г.В., Панченко С.В., Приходько С.I. Основи систем автоматизованого проектування інформаційно-вимірювальних систем [Текст]: навч. посібник. - Харків: УкрДАЗТ, 2012. - 64 с.

4. Основи наукових досліджень [Текст]: підручник / Г. В. Альошин, С.В.Лістровий, С. В. Панченко, С. І. Приходько. - Харків: УкрДАЗТ, 2012. - 340 с.

5. Gutkin, L. S. The methodology of comparative assessment of the effectiveness of the systems of satellite [Text] / L. S. Gutkin. - M.: Soviet radio, 1975.

6. Wolfe, Ph. The simplex method for quadrate programming [Text] / Ph. Wolfe // Econometrica. 1959. - Vol. 28. - №3. - P. 600-606.

Алешин Г. В.

\section{Основные преимущества} сепарабельного программирования для многомерных задач. Существенная составляющая инновационных технологий в теории информационноизмерительных систем (ИИС) и в системах их автоматизированного проектирования должна быть 
результатом решения проблем повышения еффективности, оптимизации систем и их функциональных элементов на множествах структур, сигналов и параметров по вектору показателей качества, представленных в тактико-технических требованиях, с использованием затратных показателей.

Получение этих результатов возможно за счет решения проблем системного анализа, нахождения связей вектора показателей качества ИИС с вектором технических параметров, определения проблем нечеткости, волантильности затратных показателей, учета проблемы многомерности задач, как требования к адекватности математической и физической модели ИИС, и т. д.

Но при этом во многочисленном ряду таких алгоритмов есть такое важное звено, которое в значительной степени определяет их реализацию и качество. Это - выбор лучшего метода для таких задач, которые обычно формулируются в виде математического пограммирования.

Показано, что таким методом может быть сепарабельное программирование, которое дает значительные преимущества перед другими методами.

Многочисленные публикации задач оптимизации ИИС разных назначений и их функциональных элементов по даной тематике [1-5] подтверждают возможность использования предлагаемого метода.

Ключевые слова: сепарабельное программирование, многомерные задачи.

\footnotetext{
Alyshin G. V. The main advantages of separable programming for multidimensional problems. An essential component of innovative technologies in the theory of information measuring systems (IMS) and in their computer-aided design systems should be the result of solving problems of improving efficiency, optimizing systems and their functional elements on sets of structures, signals and parameters for the vector of quality indicators presented in tactical and technical requirements, using cost indicators.

These results can be obtained through solving the problems of system analysis, finding the links between the quality index of IMS and the technical parameter vector, determining the problems of fuzziness, volatility of cost indicators, taking into account the multidimensionality of problems, as requirements for the adequacy of the mathematical and physical model of IMS, etc.

But at the same time in a large number of such algorithms there is such an important link, which largely determines their implementation and quality. This is the choice of the best method for such problems, which are usually formulated in the form of mathematical programming.
}

The paper shows that this method can be separable programming, which gives significant advantages over other methods.

Numerous publications of optimization problems of IMS of different assignments and their functional elements on this topic [1-5] confirm the possibility of using the proposed method.

Keywords: separable programming, multidimensional problems.

Надійшла 21.11.2017p.

Алешин Геннадий Васильевич, профессор, д.т.н., профессор кафедры транспортной связи Украинского государственного университета железнодорожного транспорта, Харьков, Украина. https://orcid.org/00000003-0392-9889. E-mail: aloshingv@gmail.com

\footnotetext{
Aloshin Gennadiy Vasilievich, Professor, Doctor of Technical Sciences, Professor of the Department of Transport Communication of the Ukrainian State University of Railway Transport, Kharkiv, Ukraine. https://orcid.org/0000-0003-0392-9889. E-mail: aloshingv@gmail.com
} 